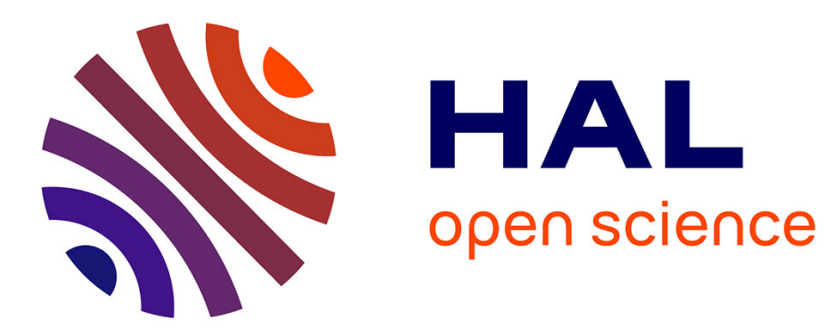

\title{
High field magnetization of TiBe2 and related compounds
}

\author{
P. Monod, I. Felner, G. Chouteau, D. Shaltiel
}

\section{To cite this version:}

P. Monod, I. Felner, G. Chouteau, D. Shaltiel. High field magnetization of TiBe2 and related compounds. Journal de Physique Lettres, 1980, 41 (21), pp.511-513. 10.1051/jphyslet:019800041021051100 . jpa-00231834

\section{HAL Id: jpa-00231834 https://hal.science/jpa-00231834}

Submitted on 1 Jan 1980

HAL is a multi-disciplinary open access archive for the deposit and dissemination of scientific research documents, whether they are published or not. The documents may come from teaching and research institutions in France or abroad, or from public or private research centers.
L'archive ouverte pluridisciplinaire HAL, est destinée au dépôt et à la diffusion de documents scientifiques de niveau recherche, publiés ou non, émanant des établissements d'enseignement et de recherche français ou étrangers, des laboratoires publics ou privés. 


\title{
High field magnetization of $\mathrm{TiBe}_{2}$ and related compounds
}

\author{
P. Monod, I. Felner $\left({ }^{+}\right)$, G. Chouteau $\left({ }^{++}\right)$and D. Shaltiel $\left({ }^{+}\right)$ \\ Laboratoire de Physique des Solides, Université Paris-Sud, 91405 Orsay, France
}

(Reçu le 24 juillet 1980, accepté le 12 septembre 1980)

\begin{abstract}
Résumé. - La mesure de l'aimantation en hauts champs (19 T) du composé intermétallique de phase Laves $\mathrm{TiBe}_{2}$ a été faite à $1,8,4,2$ et $9,6 \mathrm{~K}$ et montre une relation non linéaire entre le champ et l'aimantation. L'aimantation commence par augmenter linéairement, puis plus vite que le champ magnétique jusqu'à environ $7 \mathrm{~T}$ où une courbure vers l'axe des champs prend naissance. Par comparaison les composés $\mathrm{Ti}\left(\mathrm{Be}_{0,95} \mathrm{Cu}_{0,05}\right)_{2}$ et $\mathrm{Ti}\left(\mathrm{Be}_{0,9} \mathrm{Cu}_{0,1}\right)_{2}$ sont partiellement ferromagnétiques (ce qui confirme les données de Matthias) mais le composé $\mathrm{Ti}\left(\mathrm{Be}_{0,99} \mathrm{Cu}_{0,01}\right)_{2}$ est paramagnétique et sa susceptibilité est inférieure à celle de $\mathrm{TiBe}_{2}$. Nous concluons de ces mesures que $\mathrm{TiBe}_{2}$ est un paramagnétique dont la susceptibilité est fortement augmentée par échange et nous comparons ses propriétés en haut champ à celles de $\mathrm{Pd}$ et $\mathrm{YCo}_{2}$.
\end{abstract}

\begin{abstract}
Magnetization measurements at 1.8, 4.2 and $9.6 \mathrm{~K}$ at fields up to 19 tesla on the intermetallic Laves phase compound $\mathrm{TiBe}_{2}$ reveal a non linear behaviour of the susceptibility : the magnetization increases at first faster than the magnetic field up to $7 \mathrm{~T}$ and then curves towards the field axis. By comparison the compounds $\mathrm{Ti}\left(\mathrm{Be}_{0.95} \mathrm{Cu}_{0.05}\right)_{2}$ and $\mathrm{Ti}\left(\mathrm{Be}_{0.9} \mathrm{Cu}_{0.1}\right)_{2}$ display a ferromagnetic character whereas the compound $\mathrm{Ti}\left(\mathrm{Be}_{0.99} \mathrm{Cu}_{0.01}\right)_{2}$ appears less magnetic than $\mathrm{TiBe}_{2}$. We infer from these facts that $\mathrm{TiBe}_{2}$ is a very strongly exchange enhanced paramagnet and compare it with $\mathrm{Pd}$ and $\mathrm{YCo}_{2}$.
\end{abstract}

Since its discovery [1] $\mathrm{TiBe}_{2}$ has posed an intriguing puzzle concerning its magnetic properties. It was called an itinerant antiferromagnet by Matthias [2] on the evidence of a flat susceptibility below about $20 \mathrm{~K}$ and a Weiss temperature also about $20 \mathrm{~K}$. However neither neutron scattering [3] nor specific heat [4] could detect a phase change in the system at low temperatures. On the contrary very recent electron spin resonance experiments [5] shed considerable doubt on the initial interpretation of Matthias.

In an effort to better understand the magnetic properties of $\mathrm{TiBe}_{2}$ we have performed high field magnetization measurements at low temperatures and compared our results, with those compounds doped with $1 \%, 5 \%$ and $10 \% \mathrm{Cu}$, the latter two having ferromagnetic properties [6].

The samples have been prepared by induction melting of the constituents without further annealing [7]. The residual resistivity ratio of our $\mathrm{TiBe}_{2}$ sample between room temperature and $4.2 \mathrm{~K}$ was 19 (compared to $\sim 13$ in Ref. [2]). It thus appear that

$\left(^{+}\right)$Racah Inst. of Physics, University of Jerusalem, Israel France the comparatively slow cooling associated with the induction melting in a crucible (compared to the more rapid one inherent to the arc melting process on a cold substrate) is enough to ensure a reasonable homogeneity for the stoichiometric compound. A special Debye-Scherrer X-ray examination was performed on the $5 \% \mathrm{Cu}$ compound and showed only a single phase to be present. Atomic absorption analysis could not detect $\mathrm{Cu}$ in $\mathrm{TiBe}_{2}$ and measured $2.01 \%$ at. $\mathrm{Cu}$ in $\mathrm{Ti}\left(\mathrm{Be}_{0.99} \mathrm{Cu}_{0.01}\right)_{2}$. The samples weighted about $0.1 \mathrm{~g}$ and were of irregular, highly polycrystalline shape. Two independent measuring systems could be used on the same samples in three different magnets : two water-cooled Bitter type solenoids capable of $15 \mathrm{~T}$ and $20 \mathrm{~T}$ [8] in which the magnetization is measured by extraction of the sample between two counter wound pick up coils whose voltage is integrated, giving an overall sensitivity of $3 \times 10^{-3} \mathrm{emu}$. The magnetic field is strictly proportional to the current in the coil. The samples are immersed directly in $\mathrm{He}$ at $4.2 \mathrm{~K}$. The second apparatus is a superconducting coil capable of $1.3 \mathrm{~T}$ at $1.8 \mathrm{~K}$. The magnetization is obtained from the change of the pick up signal of a vibrating coil assembly through which the sample is slowly swept [9]. The 
absolute calibration of the vibrating coil and the field current relationship are established with a palladium reference sample.

Figure 1 shows the ensemble of our results for the magnetization (in emu/mole) at $4.2 \mathrm{~K}$ versus field for $\mathrm{TiBe}_{2}$ and the compounds with $1 \%, 5 \%$ and $10 \% \mathrm{Cu}$ substituted for $\mathrm{Be}$. Concerning the low field part of figure $1(H<3 \mathrm{~T})$ we first note the excellent agreement of the initial susceptibility of $\mathrm{TiBe}_{2}$ found here : $(8.6 \pm 0.05) \cdot 10^{-3} \mathrm{emu} / \mathrm{mole}$ at $4.2 \mathrm{~K}$ compared with that inferred from figure 1 of reference [2] i.e. $(8.5 \pm 0.1) \cdot 10^{-3} \mathrm{emu} / \mathrm{mole}$ although no detail is available in reference [2] concerning the field used for the susceptibility determination. This susceptibility is indicated by the straight line of figure 1 . No correction is made for demagnetization effect as a rough estimate shows that for $\mathrm{TiBe}_{2}$ the demagnetization factor is of the order of $10^{-3}$.

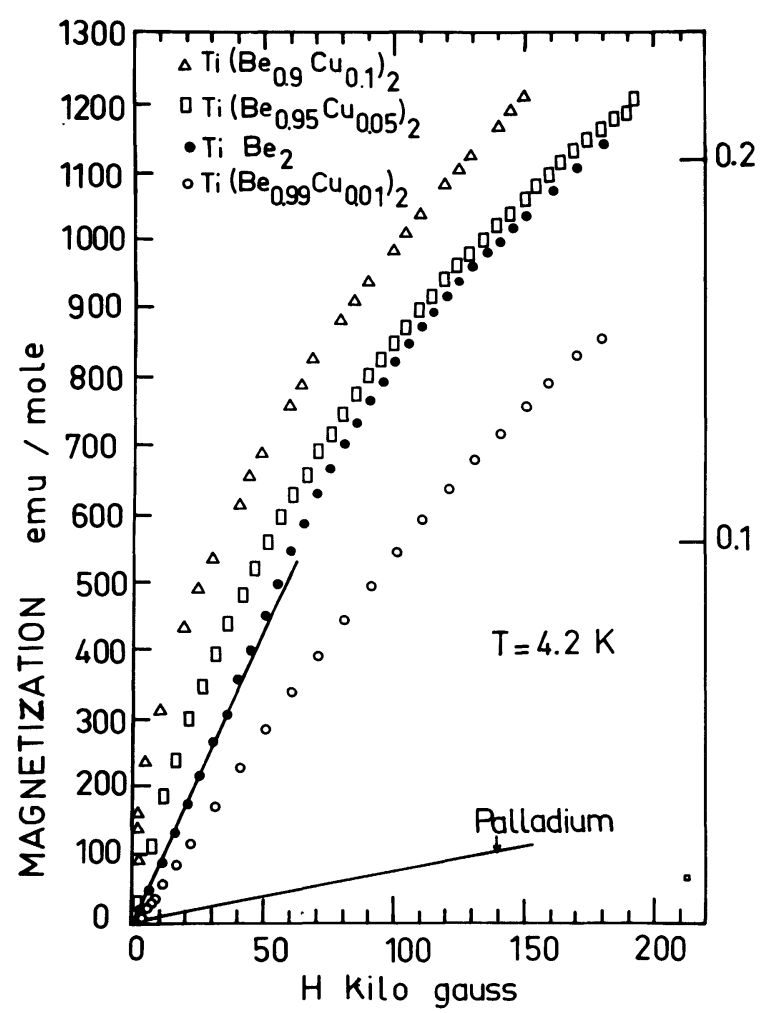

Fig. 1. - High field magnetization curve at $4.2 \mathrm{~K}$ for $\mathrm{TiBe}_{2}$ and compounds with $1 \%, 5 \%$ and $10 \% \mathrm{Cu}$ substituted for $\mathrm{Be}$. The straight line represents the initial susceptibility found by Matthias et al., reference [2]. Note that although the compounds with $5 \%$ and $10 \% \mathrm{Cu}$ are partly ferromagnetic the compounds with $1 \% \mathrm{Cu}$ is paramagnetic and has lower susceptibility than $\mathrm{TiBe}_{2}$. For sake of comparison the magnetization of palladium is indicated on the same scale which is in emu/mole (left) and Bohr magneton/formula unit (right).

This very good reproductibility is quite encouraging considering that the samples are of different origins. The striking fact of course is the non linear increase of the magnetization versus field relation for $\mathrm{TiBe}_{2}$ above roughly $3 \mathrm{~T}$. In order to display this effect more precisely and to study its temperature dependence we have plotted in figure 2 the apparent susceptibility $M / H$ as a function of magnetic field for $\mathrm{TiBe}_{2}$ at $1.8,4.2$ and $9.6 \mathrm{~K}$ (for sake of clarity we have only plotted the $4.2 \mathrm{~K}$ magnetization results in figure 1). As is evident from figure 2 this increase is temperature dependent, being most pronounced at $1.8 \mathrm{~K}$ where the initial susceptibility is

$$
(8.6 \pm 0.05) \cdot 10^{-3} \mathrm{emu} / \mathrm{mole}
$$

and increases up to $(9.3 \pm 0.05) \cdot 10^{-3} \mathrm{emu} / \mathrm{mole}$ at $6.6 \mathrm{~T}$. This maximum apparent susceptibility is already less at $4.2 \mathrm{~K}(9.0 \pm 0.05) .10^{-3} \mathrm{emu} / \mathrm{mole}$ at $6 \mathrm{~T}$, and barely detectable at $9.6 \mathrm{~K}$ near $4 \mathrm{~T}$. This maximum (field induced) susceptibility should be compared with the maximum of susceptibility observed near $10 \mathrm{~K}$ [2].

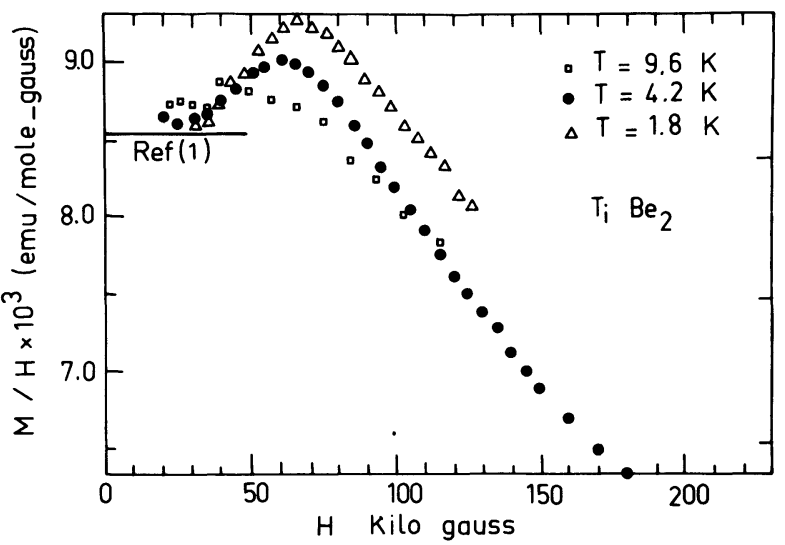

Fig. 2. - Apparent susceptibility $\mathrm{M} / \mathrm{H}$ of $\mathrm{TiBe}_{2}$ as a function of field for temperatures $1.8,4.2$ and $9.6 \mathrm{~K}$.

The second remarkable feature of figure 1 is the apparent tendency towards saturation of the magnetization exhibited by all compounds measured for fields greater than $10 \mathrm{~T}$. This effect manifests itself by a strong curvature of the initial magnetization towards the field axis until a common slope of $(3.5 \pm 0.5) \cdot 10^{-3} \mathrm{emu} / \mathrm{mole}$ is reached depending on which compound is considered. This curvature is quite unexpected as the highest magnetization reached is only $0.2 \mu_{\mathbf{B}}$ /formula unit and is very far from saturation if the maximum moment is derived from the Curie constant of reference [2] i.e. $1.64 \mu_{\mathrm{B}} /$ formula unit. The results concerning the $\mathrm{Cu} 5 \%$ and $\mathrm{Cu}$ $10 \% \mathrm{TiBe}_{2}$ compounds are somewhat less disturbing yielding a very steep magnetization increase at low field as noted previously [6]. However two facts are worth noticing : first the magnetization curve for the $\mathrm{Ti}\left(\mathrm{Be}_{0.9} \mathrm{Cu}_{0.1}\right)_{2}$ compound falls roughly a factor 2 below that of reference [6] for the same compound. We have at the moment no explanation for this apparent discrepancy. We note however that the high field slope of the magnetization (above $2 \mathrm{~T}$ ) of the compound is parallel to the susceptibility curve 
of $\mathrm{TiBe}_{2}$ : from the difference of the two curves one can infer an order of magnitude for the ferromagnetic moment of $300 \mathrm{emu} / \mathrm{mole}$ i.e. $0.05 \mathrm{Bohr}$ magneton per formula unit or $0.5 \mathrm{Bohr}$ magneton per $\mathrm{Cu}$ atom. We note that the same analysis applied to reference [6] yields about 1 Bohr magneton per $\mathrm{Cu}$ atom. Concerning the less doped compound $\mathrm{Ti}\left(\mathrm{Be}_{0.95} \mathrm{Cu}_{0.05}\right)_{2}$ the same analysis performed below $4 \mathrm{~T}$ allows as well to determine a ferromagnetic moment of $0.5 \mathrm{Bohr}$ magneton per $\mathrm{Cu}$ atom. The second fact we want to emphasize is the apparent merging of the $\mathrm{TiBe}_{2}$ magnetization curve with that of the $\mathrm{Ti}\left(\mathrm{Be}_{0.95} \mathrm{Cu}_{0.05}\right)_{2}$ system at fields near and above $10 \mathrm{~T}$ which appears as a result of the upward curvature of $\mathrm{TiBe}_{2}$ magnetization curve. Finally the apparent lowering of the initial susceptibility of $\mathrm{Ti}\left(\mathrm{Be}_{0.99} \mathrm{Cu}_{0.01}\right)_{2}$ which is $5.6 \times 10^{-3} \mathrm{emu} / \mathrm{mole}$ compared to $8.6 \times 10^{-3} \mathrm{emu} / \mathrm{mole}$ for $\mathrm{TiBe}_{2}$ confronts us with a real puzzle.

We have at present no convincing explanation for this ensemble of results. We consider that the hypothesis of $\mathrm{TiBe}_{2}$ being an itinerant antiferromagnet has been already very much shaken and the non linear behaviour of the magnetization curve observed here is of little help for this interpretation as none of the orders magnitudes for a combination of spin flop field and saturation effect agree with anything reasonable. On the other hand the interpretation of $\mathrm{TiBe}_{2}$ as a very strongly exchange enhanced material [5] although in much better position for explaining the specific heat, the neutron diffraction, the occurrence of ferromagnetism and the E.S.R. data, will require considerable effort to cope with the non linear $M^{3}$ and $M^{5}$ terms in the free energy derivatives. Such an attempt has been already tried by Bloch et al. [10] in order to account for the $H^{3}$ terms present in the magnetization curves of Laves phases compounds $\mathrm{YCo}_{2}$ and $\mathrm{LuCo}_{2}$ (further studied by [11]), Pd [12] and was anticipated for antiferromagnetic $\mathrm{TiBe}_{2}$ [13]. In this description the relation between $M$ and $H$ is derived from a Landau expansion as :

$$
\frac{\mathrm{d} F}{\mathrm{~d} M}=H=\frac{1}{\chi} M+B M^{3}
$$

where both $\chi$ and $B$ may be temperature dependent.
Assuming a small deviation from linearity this relation is inverted to yield

$$
M=\chi H-B \chi^{4} H^{3} .
$$

\begin{tabular}{|c|c|c|c|}
\hline Metal & $\operatorname{Pd}\left({ }^{a}\right)$ & $\mathrm{YCo}_{2}\left({ }^{b}\right)$ & $\mathrm{TiBe}_{2}\left({ }^{(c)}\right.$ \\
\hline$B(\mathrm{emu} / \mathrm{mole})$ & $-1.6 \times 10^{-4}$ & $-5 \times 10^{-4}$ & $-0.3 \overline{4} \times 10^{-4}$ \\
\hline$(4.2 \mathrm{~K})$ & & & \\
\hline $\begin{array}{c}\chi(\mathrm{emu} / \mathrm{mole}) \\
(4.2 \mathrm{~K})\end{array}$ & $0.72 \times 10^{-3}$ & $1.7 \times 10^{-3}$ & $8.6 \times 10^{-3}$ \\
\hline$B \chi M_{0}^{2}\left({ }^{d}\right)$ & -3.6 & -26 & -9.1 \\
\hline \multicolumn{4}{|c|}{$\begin{array}{l}\left({ }^{a}\right) \text { From reference [12]. } \\
\left({ }^{b}\right) \text { From reference [10]. } \\
\left({ }^{c}\right) \text { This work. }\end{array}$} \\
\hline
\end{tabular}

Table I. - Comparison of cubic magnetization terms.

We present in table $\mathrm{I}$ a compilation of the parameter $B$ for $\mathrm{Pd}, \mathrm{YCo}_{2}$ and $\mathrm{TiBe}_{2}$ from the available data. We note that in our case this term is only well apparent in a restricted field interval as it is overwhelmed by higher order terms quite soon, contrary to Pd and to the Co compounds. We remark however that the order of magnitude of $B$ varies inversely with the susceptibility of the host thus indicating that such a cubic curvature may be a more general property of strongly paramagnetic systems as soon as a given fraction of the saturated magnetization is reached by the appropriate field. This is clearly seen by rewriting the $M-H$ relation in a dimensionless manner :

$$
\frac{M}{M_{0}}=\frac{\chi H}{M_{0}}-\left(B \chi M_{0}^{2}\right)\left(\frac{M}{M_{0}}\right)^{3} .
$$

There is a priori no relation between $B$ and $\chi$ as they belong to different terms of the series expansion of the magnetic free energy so that other cases are needed to test this fact.

Acknowledgments. - We are very indebted to R. Tur for his technical assistance with the experiments using the vibrating coil set up. The chemical analysis was performed by P. Amiot and J. Palleau. We thank them very much for their help.

\section{References}

[1] Saji, H., Yamadaya, T. and Asanuma, M., J. Phys. Soc. Japan 21 (1966) 255.

[2] Matthias, B. T., Giorgi, A. L., Struebing, V. O. and Smith, J. L., J. Physique Lett. 39 (1978) L-441.

[3] Rakhecha, U. C., Felcher, G. P., Sinha, S. K., Smith, J. L. and Matthias, B. T., Solid State Commun. 33 (1980) 495.

[4] Stewart, G. R., Matthias, B. T., Giorgi, A. L., Szklarz, E. G. and Sмiтh, J. L., Solid State Commun. 30 (1979) 709 .

[5] Shaltiel, D. and Monod, P., 6th Int. Conf. on Transition Metals, Leeds (1980) and to be published.

[6] Giorgi, A. L., Matthias, B. T., Stewart, G. R., Acker, F. and SMITH, J. L., Solid State Commun. 32 (1979) 455.
[7] This preparation differs from reference [2].

[8] Rub, P., Picoche, J. C. and Schneider-Munteau, H. I., Coll. Int. CNRS no 242 Physique sous champs magnétiques intenses (1974).

[9] Chouteau, G. and TuR, R., SNCI report 1977 (unpublished).

[10] Bloch, D., Edwards, D. M., Shimizu, M. and Volron, J., J. Phys. F 5 (1975) 1217.

[11] Schinkel, C. J., J. Phys. F 8 (1978) L 87.

[12] Muller, F. A., Gersdorf, R. and Roeland, L. W., Phys. Lett. 31A (1970) 424.

[13] Wohlfarth, E. P., J. Magn. Mag. Mat. 20 (1980) 77 